\title{
OXORHENIUM(V) COMPLEXES WITH A S-BENZYLDITHIOCARBAZATE LIGAND: SYNTHESIS AND CHARACTERIZATION
}

\author{
Viana, R. B. ${ }^{1}{ }^{*}$; Fernandes, A. G. D. A. ${ }^{2}$; Lemos, S. S. ${ }^{3}$ Gatto, C. C. ${ }^{3}$; Lang, E. S. ${ }^{4}$; \\ Hagenbach, A. ${ }^{5}$; Abram, U. ${ }^{5}$; da Silva, A. B. F. ${ }^{1}$; Deflon, V. M. ${ }^{1}$ \\ ${ }^{1}$ Instituto de Química de São Carlos, Universidade de São Paulo, São Carlos, SP, Brasil \\ 2 Departamento de Ciências Exatas e Tecnológicas, Universidade Estadual de Santa Cruz, Ilhéus, SP, Brasil \\ ${ }^{3}$ Instituto de Química, Universidade de Brasília, Brasília, DF, Brasil \\ ${ }^{4}$ Departamento de Química, Universidade Federal de Santa Maria, Santa Maria, RS, Brasil \\ ${ }^{5}$ Institut für Chemie, Freie Universität Berlin, Berlin, Germany
}

*rommelbv@yahoo.com.br

In this study was performed the synthesis and characterization of two new oxorhenium(V) complexes with the 5-hydroxy-3-methyl-5-phenyl-pyrazoline-1-(S-benzyldithiocarbazate) ligand $\left(\mathrm{H}_{2}\right.$ bdtc): $\mathrm{ReOBr}(\mathrm{bdtc})$ (triphenylphosphine) (1) and $\mathrm{ReO}$ (bdtc)(cysteamine) (2). In the characterization of the structures were employed different techniques like elemental analysis, spectroscopic methods (ESI-MS, IR, ${ }^{1} \mathrm{H}$ and ${ }^{31} \mathrm{P}$ NMR), and by X-ray diffraction. In addition, a detailed quantum chemical study will support in understanding the different electronic properties of the both compound, which will clarify the experimental data available for these molecules. The $\mathbf{1}$ purple prism monocrystals was crystallized with a monoclinic system and a $\mathrm{P} 2_{1} / \mathrm{n}$ space group. The complex $\mathbf{2}$ is a different case, where it was observed red prism monocrystals with a $\mathrm{P} 2 / \mathrm{c}$ space group after the crystallization. Comparing both structures, the main information we can take is the different coordination arrangements that bdtc ${ }^{2-}$ can assume, where is detected a planar one for $\mathbf{1}$ and a facial one for the complex $\mathbf{2}$. Moreover, understanding the second order perturbation energy $\left(\mathrm{E}_{2}\right)$ allows the determination of the strength between donor and acceptor NBO, while the Quantum Theory of Atoms in Molecules will be employed in the understanding of intermolecular interactions predicted between the ligands. 